\title{
Influência dos eventos internacionais nas políticas ambientais brasileiras: recuperação histórico-conceitual da definição de desenvolvimento
}

Os anos 1960 foram e serão lembrados, por várias gerações, como o start mundial de enfrentamento à grave e evidente crise ambiental, originada nas décadas anteriores, pela qual passava a humanidade. Nas décadas seguintes, decorrente de uma série de desastres e desequilíbrios ambientais, só veio a agravar-se, como resultado do modelo de desenvolvimento da cultura ocidental, passando a se constituir fator de maior preocupação dos países desenvolvidos e em desenvolvimento, bem como da comunidade científica, levando-os a repensar novas estratégias para o enfrentamento desta problemática em escala mundial. 0 presente artigo se propõe a realizar uma recuperação histórica dos principais eventos internacionais que contribuíram para o debate sobre a problemática ambiental, na construção do conceito de desenvolvimento, capaz de responder e redirecionar a construção de um novo pacto societário de caráter planetário e, de conciliar: desenvolvimento econômico, uso eficiente dos recursos naturais e equidade social. O presente artigo identificou a influência que os eventos globais tiveram na constituição do conceito Desenvolvimento Sustentável. Esse conjunto de acontecimentos, somados a pensadores que influenciaram, como uma nova ordem, o marco jurídico ambiental dos países e a construção de políticas ambientais no âmbito global, especialmente no Brasil. Portanto, demonstramos, pela análise de três importantes legislações brasileiras, que tais eventos e o conceito de desenvolvimento sustentável estão presentes no Brasil de maneira central.

Palavras-chave: Desenvolvimento sustentável; Políticas públicas ambientais; Problemática ambiental; Meio ambiente.

\section{Influence of international events in brazilian environmental policies: historical-conceptual recovery of the definition of development}

The 1960s have been and will be remembered for generations as the world start to confront the serious and evident environmental crisis, originated in the previous decades, which humanity was going through. In the following decades, as a result of a series of environmental disasters and imbalances, it only worsened as a result of the model of development of Western culture, becoming a factor of major concern for developed and developing countries, as well as the community. leading them to rethink new strategies for tackling this problem on a worldwide scale. This paper proposes to make a historical recovery of the main international events that contributed to the debate about the environmental problem, in the construction of the concept of development, able to answer and redirect the construction of a new planetary pact and to reconcile : economic development, efficient use of natural resources and social equity. The present article identified the influence that global events had on the constitution of the Sustainable Development concept. This set of events, together with thinkers who influenced, as a new order, the environmental legal framework of the countries and the construction of environmental policies at the global level, especially in Brazil. Therefore, we demonstrate, by analyzing three important Brazilian legislations, that such events and the concept of sustainable development are centrally present in Brazil.

Keywords: Sustainable development; Environmental public policies; Environmental problem; Environment.

Topic: Área Temática

Reviewed anonymously in the process of blind peer.
Received: 10/02/2019

Approved: 25/03/2019
Ivan Penteado Dourado (10)

Universidade de Passo Fundo, Brasil

http://lattes.cnpq.br/7379643381730867

http://orcid.org/0000-0002-4529-831X

ivan.dourado@acad.pucrs.br

Ademar de Oliveira Marques

Universidade de Passo Fundo, Brasil

http://lattes.cnpq.br/5085385174457406

http://orcid.org/0000-0003-1949-1711

ade.marquea@terra.com.br
Referencing this:

SOBRENOME, N. N.; SOBRENOME, N. N.. Influência dos eventos internacionais nas políticas ambientais brasileiras: recuperação histórico-conceitual da definição de desenvolvimento. Revista Ibero Americana de Ciências Ambientais, v.10, n.2, p.254-270, 2019. DOI: http://doi.org/10.6008/CBPC2179-6858.2019.002.0022 


\section{INTRODUÇÃO}

A problemática referente às questões ambientais mostra-se central, não apenas pela dimensão do impacto do modelo econômico e desenvolvimentista disseminado nas últimas cinco décadas, mas por permitir identificar as reações governamentais de cada país. Segundo Leff (2006), nasce de uma "crise de civilização da cultura ocidental", da modernidade sobre as novas formas do conhecimento e da forma como a economia globalizada vem intervindo na natureza". Surgindo um novo modelo de civilização hegemônica, cuja relação com o meio ambiente se dá pelas relações de mercado, vindo a se intensificar a partir da Revolução Industrial, alicerçada no desenvolvimento de novas tecnologias, nas novas formas de produção, organização de trabalho, mecanização agrícola, industrialização, urbanização, na busca de um mercado mundial de produção e consumo em escala global (WOLKMER et al., 2011). Ainda de acordo com Leff (2006), não se trata de uma catástrofe ecológica e nem uma crise econômica, mas do próprio desequilíbrio e da desarticulação existente no mundo, levando pela coisificação do ser humano aliado a exploração exaustiva dos recursos naturais.

Conforme expressa Santos (2007), sobre as linhas abissais modernas, "a primeira grande transformação, da propriedade e do direito de propriedade da era moderna, o capitalismo, a expansão da propriedade sobre as coisas e sobre os meios de produção, transformou o controle sobre as coisas e o controle sobre as pessoas". Karl Renner (citado por SANTOS, 2007) "o proprietário das máquinas transformou-se no proprietário da força de trabalho dos trabalhadores que nelas operam".

Theis (1996), em seu trabalho "Considerações sobre os limites energéticos do crescimento econômico", numa análise sobre as bases da sociedade moderna, como a crescente ciência geradora de conhecimento, a afirmação do econômico na base das relações sociais, o consumismo, a supremacia e as influências do econômico nas relações sociedade e meio ambiente, ao analisar a ascensão do padrão de mercado da sociedade moderna, traz como referência vários teóricos e pensadores sobre a sociedade de mercado (o mercado auto regulável), definida como: "é uma totalidade sem sujeito.. que emerge da composição das ações humanas, e na qual o interesse egoísta de cada um se funde com o interesse de todos"; e, "não poderia existir em qualquer tempo sem aniquilar a substância humana e natural da sociedade". O sistema econômico, historicamente, esteve mergulhado nas relações sociais de um modo geral, passando a "dirigir a sociedade como se fosse um acessório de mercado" (THEIS, 1996), assim, o que se percebe é que são relações sociais que estão envolvidas no sistema econômico, tornando-se, assim, uma ameaça aos seres humanos, que são controlados e dirigidos pelo mercado.

Assim, a partir da Revolução Industrial, grandes consequências e desafios afloram no século XX, em que a população mundial cresceu quatro vezes mais e a produção aumentou quarenta vezes e, paralelamente, o uso de combustíveis fosseis dezesseis vezes, sem contar o aumento de trinta e cinco vezes a captura de peixes e o consumo de água aumentando nove vezes (WOLKMER et al., 2011). Isto revela uma corrida desenfreada e sem precedente na história da humanidade para a exploração dos recursos naturais, elevando os níveis de risco do esgotamento do nosso planeta. Ao mesmo tempo este cenário de demandas 
e necessidades veio a favorecer ao "padrão de mercado emergente" voltado aos próprios interesses dos indivíduos e acumulação de riquezas, terreno fértil ao desenvolvimento capitalista, o que mais tarde passou a se chamar de crescimento econômico. Levando milhões de pessoas a pobreza, desemprego em grande escala, conflitos sociais, produzindo uma sociedade de massa. Esta disputa e pressão pela obtenção dos recursos naturais tende a agravar-se pela menor oferta de insumos fornecidos pelos ecossistemas (WOLKMER et al., 2011; THEIS, 1996).

Dessa forma nos transformamos em sociedades de consumo, "o consumo é o verdadeiro sujeito" e este, consequentemente, objeto do mercado. As pessoas são transformadas em consumidores, utilitaristas, levadas a sentirem necessidade das coisas, das mercadorias, e estas se tornaram um fim em si. O consumismo passou a ser parte da sociedade moderna, um estranho hábito, segundo Arendt (2007) “uma economia de desperdício, na qual todas as coisas devem ser devoradas e abandonadas quase tão rapidamente quanto surgem no mundo [...] a canalização de forças naturais para o mundo humano destruiu a própria finalidade do mundo".

Harari (2018) em seu livro "Sapiens, uma breve história da humanidade", se referindo a Revolução Industrial, diz que ela inaugurou "novos caminhos para converter energia e produzir bens", trazendo liberdade ao ser humano de sua dependência aos ecossistemas e habitats. Espécies foram destruídas para que o mundo fosse moldado para atender às necessidades do Homo sapiens, tornando o nosso planeta "num shopping center de plástico e de concreto". A chamada economia capitalista moderna, nos tornou bons consumidores, compramos aquilo de que não precisamos, e compramos para nos sentir incluídos, os bens e consumo se tornaram mediadores nas relações sociais, favorecendo desta forma ao crescimento econômico, e trazendo grave consequências ao meio ambiente, não à escassez dos recursos naturais, mas a sua degradação, a uma 'desordem ecológica', aquecimento global, poluição do ar, aumento do nível dos oceanos, destruição de habitats e extinção de outras espécies, ou seja, uma ameaça a sobrevivência do próprio Homo sapiens (HARARI, 2018).

O presente artigo, objetiva apresentar uma recuperação histórica e política, apresentando a conexão entre eventos mundiais e internacionais e sua influência nas legislações e políticas ambientais brasileiras. Focando na centralidade da definição de desenvolvimento sustentável no contexto nacional, procuramos relevar que o impacto dos eventos não é tão claro como a influência dos acordos internacionais norteados pelo conceito de desenvolvimento sustentável, mas que os primeiros, influenciaram significativamente o marco regulatório do Brasil. Essa influência é tanta que, após a publicação do relatório Brundtland de 1987, o país em seu processo constituinte incorporou este conceito no texto da Constituição Federal promulgada em 1988, artigo 225: "Todos têm direito ao meio ambiente ecologicamente equilibrado, bem de uso comum do povo e essencial à sadia qualidade de vida, impondo-se ao poder público e à coletividade o dever de defendê-lo e preservá-lo para as presentes e futuras gerações" (BRASIL, 1988). Por outro lado, conforme expressa Marconatto (2013), este conceito esteve entrincheirado entre biocentrístas e antropocentristas, desenvolvidos e em desenvolvimento. E os eventos internacionais, e em especial, a Convenção sobre a Diversidade Biológica (CDB, 1992), contribuíram para proteção da biodiversidade, sua normatização, o uso 
sustentável e gestão dos recursos naturais, e o Programa Agenda 21 Global como experiências de mobilização social para a construção das políticas ambientais no Brasil e no mundo. Essa relação entre eventos, acontecimentos e as políticas ambientais, será o foco principal deste estudo.

\section{METODOLOGIA}

Este trabalho se caracteriza como estudo bibliográfico, realizado por meio de Pesquisa Exploratória, perante levantamento da literatura existente relacionado ao tema proposto. A pesquisa exploratória Piovesan et al. (1995) consiste em esclarecer, desenvolver conceitos e ideias, e tem finalidade também de formular problemáticas e hipóteses para futuros estudos. O uso de metodologias que envolvem o mapeamento bibliográfico exploratório, documental, foi fundamental, para o cruzamento das influências propostas na presente pesquisa.

No seu artigo intitulado "Estudos de revisão: implicações conceituais e metodológicas", Vosgerau et al. (2014), ressaltam a importância dos estudos de revisão, afirmando que estes contribuem para esclarecer e resumir as principais obras de literaturas existentes em determinadas áreas. Além de fornecer um panorama histórico sobre um tema ou assunto. "Esses estudos podem conter análises destinadas a comparar pesquisas sobre temas semelhantes ou relacionados; apontar a evolução das teorias, dos aportes teórico metodológicos, e sua compreensão em diferentes contextos" (VOSGERAU et al., 2014). Neste caso, para aprofundar e contribuir com a análise do material pesquisado, o presente estudo percorreu o estado da arte realizando um conjunto de recuperações históricas, seguindo eventos e pensadores referência mais citados, recuperando os eventos que serão posteriormente indicados.

Diante do exposto na introdução, emerge a seguinte problemática: Quais legislações e políticas ambientais brasileiras surgiram influenciadas pelos eventos internacionais realizados pelo sistema ONU (Organização das Nações Unidas) sobre a pauta meio ambiente e sustentabilidade?. É com essa problemática que o presente artigo pretenderá discorrer.

\section{Políticas ambientais, uma recuperação histórica e política}

Segundo identificamos na introdução, as décadas de 60 e 70 diante da preocupação com o uso e o acelerado esgotamento dos recursos naturais, e a sobrevivência do planeta (WOLKMER et al., 2011; SACHS, 1993), alguns desafios foram postos, tais como: a gestão do meio ambiente para atenuar o impacto do esgotamento aos recursos naturais, o acelerado crescimento populacional nos centros urbanos, o uso adequado do conhecimento tecnológico na economia para atenuar as desigualdades socioeconômicas e ambientais, a democracia participativa em todos os níveis, do local ao global. Que Sachs (1993) definiu como: “Um novo equilíbrio precisa ser encontrado entre todas as formas de capital - humano, natural, físico e financeiro, bem como os recursos institucionais e culturais".

No entanto, as ideias e conceitos de sustentabilidade, tem sua origem a partir da década de 60 , onde levantou-se uma série de discussões sobre a natureza e a finitude dos recursos naturais, trazendo para o debate os estudos socioeconômicos, e para a agenda econômica-política, a crise ambiental decorrente dos 
efeitos provocados pela industrialização, pelos eventos catastróficos. Pott et al. (2017) e Nascimento (2012), discorrendo sobre os eventos catastróficos internacionais que impactaram o meio ambiente e às pessoas em três décadas no pós Revolução Industrial, e que só a partir dos anos 50 e 60 é que a questão ambiental e os impactos decorrentes da poluição nuclear, das atividades de produção e crescimento desordenado da população, passaram a serem debatidas na sociedade. Principais eventos internacionais de poluição do ar e contaminação da água: Poluição atmosférica no Vale do Meuse na Bélgica (1930, 60 pessoas mortas), Lançado pelos EUA bombas nucleares sobre as cidades de Hiroshima e Nagasaki no Japão (1945, 2.000 pessoas mortas e devastação ambiental), Smog, conhecida como a 'nevoa matadora' em Londres (1952, 4.000 mortes), Contaminação da água da Baía de Minamata no Japão (1956, 107 mortes e registros de mais de 3.000 casos) (NASCIMENTO, 2012; POTT et al., 2017).

Diversas correntes de pensamento ampliam o debate. Alonso et al. (2002), citando Hanningan (1995), recupera os estudos de vários teóricos focados na crítica acerca da busca em colocar a questão ambiental no centro da teoria social e sua forma de interpretação, tais como os marxistas ecológicos: o capitalismo provocou uma série de problemas sociais e ambientais, já para os neomarxistas: veem sob o prisma da economia política, a produção da natureza como processo estruturador do capitalismo contemporâneo (SCHNAIBERG, 1980; O'CONNOR, 1994). E os que divergem, colocando a existência da contradição entre expansão econômica e equilíbrio ecológico, capital, trabalho e natureza (BUTTEL, 1997; GOLDMAN et al., 2000), apontando para um caráter mais normativo que analítico, presente nos estudos da teoria da modernização ecológica (MOL et al., 2000), os quais propõe mudanças no modelo econômico e mudança no padrão de consumo (ALONSO et al., 2002).

Estes acontecimentos, discussões e estudos construíram um ambiente favorável à emergência da definição de 'ecodesenvolvimento', que tem em Ignacy Sachs, 1986, seu defensor, onde faz a crítica da insustentabilidade do capitalismo, apontando para a necessidade de mudança do padrão de desenvolvimento socioeconômico, que fosse capaz de conciliar o econômico, o social e o ambiental (ALONSO et al., 2002). Esta crise acabou gerando nos países, sérios problemas e danos na economia e na própria sociedade, tais como, recessão, desemprego e inflação, levando ao questionamento a respeito dos modelos de desenvolvimento adotados pelos mesmos (PHILIPPI JR et al., 2013). É nesse contexto que emergem os eventos internacionais.

\section{Eventos e seus marcos histórico-ambientais}

Os eventos internacionais e nacionais mais importantes sobre o tema ambiental emergem a partir da década de 60 , contribuindo para a construção de um novo entendimento chamado posteriormente de 'desenvolvimento sustentável'. Ainda nesse período, a bióloga e escritora norte-americana Rachel Carson, em seu livro intitulado 'Silent Spring', escrito em 1962, destaca a sua preocupação e a necessidade de se respeitar o ecossistema em que vivemos para proteger a vida humana e o meio ambiente. $O$ seu livro, que em 1973 já estava traduzido para mais de 15 países, que não só promoveu uma reação de movimento ambientalista mais radical e de base social mais ampla de posições diferentes entre 'preservacionistas' e 
'conservacionistas', mas também provocou e contribuiu com a comunidade cientifica internacional, o debate sobre os efeitos negativos da ação desordenada do homem sobre a natureza, e um alerta do impacto do uso de "agrotóxicos" para o homem e para o meio ambiente. (NASCIMENTO, 2012). Segundo declara Carson: "A rapidez da mudança e a velocidade com que novas situações se criam acompanham o ritmo impetuoso e insensato do Homem, ao invés de acompanhar o passo deliberado da Natureza." (CARSON, 1969). No Brasil, a primeira edição do Primavera Silenciosa, foi publicada em 1964, e somente em 1971, por meio da Câmara dos Deputados (Comissão Especial sobre Poluição Ambiental), foi realizada em Brasília, o I Simpósio sobre Poluição Ambiental. Em nosso contexto recente, o Brasil que lidera o consumo de agrotóxicos, este livro se torna atual e necessário. Somente em 2009 o país proíbe o uso do DDT (NASCIMENTO, 2012; POTT et al., 2017).

\section{Clube de Roma}

Num clima de crescente preocupação com os efeitos do impacto e da degradação do meio ambiente, em 1968 é fundado pelo italiano industrial Aurélio Peccei, o 'Clube de Roma', formado por empresários, políticos e cientistas sociais, onde em 1971, solicitou ao Massachusetts Institute of Tecnology (MIT), um estudo que envolvendo simulações computacionais, afim de mapear a interação humana com o meio ambiente, tendo como parâmetros o aumento populacional e o esgotamento dos recursos naturais. Estes estudos coordenados por Donella Meadows, Denis Meadows e Jorgen Randers, resultaram no chamado Relatório Meadows ou Limits to growth, 1972, cujo objetivo era abrir discursões para questões ambientais, afim de que a sociedade refletisse sobre seu impacto no planeta e em como esse impacto seria percebido pelas gerações futuras, recomendava crescimento zero da atividade econômica e da população, como forma de garantir a continuidade do planeta e da espécie humana (MEADOWS, 1972; PHILLIPI JR et al., 2013; RISSATO et al., 2010).

A conclusão dos modelos utilizados na análise pelo grupo de estudos, foi que, se a humanidade continuasse a consumir recursos naturais no mesmo ritmo da época, por consequência da crescente industrialização, os mesmos recursos atingiriam a escassez em cerca de 100 anos (DE MARCO et al., 2017). A recomendação deste relatório apontava para o desaceleramento do crescimento econômico e a adoção de políticas ambientais que restringissem a expansão das atividades econômicas. $O$ grupo foi duramente criticado pela comunidade internacional pelos resultados apresentados, sendo acusados de frear o crescimento econômico mundial, especialmente pelos países em desenvolvimento (RISSATO et al., 2010; ROMEIRO, 2012).

\section{Conferência da biosfera}

Outro evento importante que também merece destaque ocorrido em 1968, a Organização das Nações Unidas para a Educação, a Ciência e a Cultura (UNESCO) organizou a Conferência sobre a Biosfera em Paris, sendo o primeiro com caráter intergovernamental, trazendo para o debate a questão do desenvolvimento e a perda da qualidade do meio ambiente, reconceituando o termo utilizado por 'natureza', 
melhorar a relação homem-natureza e meio ambiente e reduzir a perda da biodiversidade, dando assim, sentido mais amplo, uma vez que poderia ser debatido não só pela comunidade científica, mas também econômica, política e social. Como resultado foi lançando pela UNESCO em 1971, o Programa Homem e Biosfera (MaB) sigla em inglês, Man and Biosphere Programme. Um programa de cooperação científica internacional, que terá impactos profundos nas discussões posteriores em outros países.

No Brasil, o MaB teve início em 1974 com a instituição da Comissão Brasileira para o Programa MaB (Cobramab), e somente em 1991 foi criada a primeira Reserva da Biosfera (RB) de Mata Atlântica. Por meio da Lei Federal no 9.985/2000, foi criado o Sistema Nacional de Unidades de Conservação (SNUC) onde prevê a criação das Reservas da Biosfera. O país possui seis RBs, uma em cada bioma, cobrindo uma área de 1.771.014 KM² : Mata Atlântica (RBMA, entre 1991 e 2002), Cerrado (RBC, entre 1993 e 2002), Pantanal (RBT, em 2000), Caatinga (RBCAAT, em 2001), Amazônia Central (RBAC, em 2001) e Serra do Espinhaço (RBSE, em 2005), com a exceção do bioma Pampas (GANEM, 2011).

\section{Painel de founex}

Nestes quase 10 anos de debates, ocorridos durante toda a década de 60 , serviram para o amadurecimento e sistematização dos diversos conceitos e conhecimentos construídos nas áreas do direito, economia, política, ambiental e social. Com este sentido, por meio de um Comitê Preparatório formado por representantes de 27 países, dentre estes o Brasil, que passou a realizar reuniões preparatórias a Conferência, como por exemplo, a reunião especial do Painel de Especialistas em Desenvolvimento e Meio Ambiente, em Founex, Suíça, em junho de 1971. O Painel de Founex como ficou conhecido, facilitou os acordos que seriam fechados em Estocolmo no ano seguinte, por enfatizar que meio ambiente e desenvolvimento eram os dois lados da mesma moeda, e que o meio ambiente era um problema relacionado não somente com os aspectos biofísicos, mas também com os aspectos socioeconômicos (ONU, 1971).

Tanto o relatório do Clube de Roma Limites do Crescimento (MEADOWS, 1972), quanto o relatório Founex (REPORT FOUNEX, 1971), foram documentos fundamentais para embasar a realização em 1972 em Estocolmo, a Conferência das Nações Unidas sobre Meio Ambiente Humano, com a tarefa de dar projeção e construir entendimentos acerca da relação entre meio ambiente e desenvolvimento, 'crescimento quantitativo' e 'desenvolvimento qualitativo', buscando superar os conceitos e debates do Ecologismo e Economicismo presentes nos debates da década anterior (SACHS, 1993).

\section{Conferência cnumad}

Assim, a primeira Conferência das Nações Unidas sobre o Homem e o Meio Ambiente, realizado em Estocolmo em 1972, com caráter intergovernamental e escala global, tornou-se um marco importantíssimo, um 'divisor de águas' para a necessidade de construção de políticas ambientais, e a primeira tomada de consciência em escala mundial das fragilidades dos ecossistemas. Esta Conferência chamou a atenção dos países presentes e para o mundo, que a ação do homem tem causado danos nocivos ao meio ambiente, criando severos riscos para o bem-estar e sobrevivência da humanidade e do planeta. Importante destacar 
como resultado desta conferência, foi a criação do Programa das Nações Unidas para o Meio Ambiente (PNUMA), organismo da ONU, financiado pelo Conselho Econômico e Social, que exerceria protagonismo e liderança nos debates intergovernamentais na busca de promover e construir políticas globais de desenvolvimento sustentável (RIBEIRO, 2001; SCHNEIDER, 2015).

\section{Relatório Brundtland}

Os debates decorrentes da CNUMAD, 1972, e o conceito de desenvolvimento sustentável, avançaram a partir dos trabalhos do PNUMA (1973), que tinha como tarefa delinear e construir estratégias ambientais para o século 21, e da Comissão Mundial para o Meio Ambiente e Desenvolvimento (WCED), instituída pela Assembleia Geral da ONU em 1985, com representação dos estados-membros, sendo o Brasil representando pelo ambientalistas Paulo Nogueira Neto (in memoriam). Presidida pela primeira ministra norueguesa GroBrundland que chefiou esta comissão, e que culminou com a apresentação do relatório e protocolo 'O Nosso Futuro Comum' (Our Common Future, 1987), mais conhecido como o relatório Brundtland, disseminando assim, o conceito de desenvolvimento sustentável, baseado em três 'pilares: as dimensões econômica, social e ambiental, ou seja, aquele desenvolvimento que é capaz de atender as necessidades das atuais gerações, sem comprometer as necessidades das futuras gerações (BRUNDTLAND, 1987; MARCO et al., 2017; NASCIMENTO, 2012).

Este conceito, longe de ser consenso por alguns autores e críticos de que o relatório Brundtland representa mais aos interesses econômicos dos países ricos, usando a bandeira socioambiental. Outros autores com uma visão mais antropocêntrica, consideram os seus resultados voltados para uso tecnológico e do livre mercado como solução para os problemas sociais. E que o desenvolvimento sustentável está entrincheirado entre as visões biocentrístas, em que a natureza tem primazia sobre o homem e a antropocentristas em que o homem comanda a natureza.

\section{ECO 92}

Esse evento constitui um ponto fundamental nos achados da presente pesquisa, pois fortalece o papel do Brasil no protagonismo e influência nas políticas aqui adotadas posteriormente. Sob a influência e importância do Relatório Brundtland (1987), da Conferência de Estocolmo (1972) e da Agenda Global sobre as questões ambientais, debatidas não só pelos organismos do sistema ONU, como o PNUMA, pelos governos nacionais, pelos diversos setores do mercado, pela comunidade científica internacional, mas especialmente pelas organizações da sociedade civil e movimentos ambientalistas, sociais e populares. A Assembleia Geral da ONU em 1989, acatando uma solicitação do governo brasileiro, convoca uma conferência sobre os temas ambientais, o que se tornaria o maior e mais importante evento em escala global, A Conferência das Nações Unidas sobre o Meio Ambiente e Desenvolvimento, também chamada de Cúpula da Terra ou ECO-92, realizada em 1992 no Rio de Janeiro, com a presença de representantes e chefes de estado de 187 nações. Conforme destacado, os acordos, tratados, convenções, declarações e agendas, contribuíram mundialmente para a difusão e influenciaram para a preocupação com as questões ambientais e a sua proteção de 
diferentes formas entre os países. Muito embora não sejam consenso, especialmente pelos limites apontados para o modelo de expansão econômica, somam-se as contradições entre os países desenvolvidos e em desenvolvimento, quando alguns se negam assinar em 2007, o chamado Protocolo de Kyoto (IPCC Panel for Climate Change), importante documento de diretrizes e metas para redução de emissão de gases de efeito estufa, promotores principais do aquecimento global, causado pelas atividades de desenvolvimento industrial (ONU, 1992; MARCO et al., 2017; NASCIMENTO, 2012).

Philippi Jr et al. (2013), ressalta que a Rio 92, tornou-se um "marco na universalização da temática ambiental" por apontar para o direito das pessoas viverem em um ambiente com qualidade, dignidade e bem-estar e que o conceito de 'desenvolvimento sustentável' se consolidou nesta conferência, orientado para um desenvolvimento em que os recursos são repensados pensando nas futuras gerações (PHILIPPI JR et al., 2013).

Nesta mesma linha de pensamento, Sachs (1993), afirma que as pressões das organizações civis, e de partidos que levantaram a ideologia da bandeira ambiental, foram fundamentais neste processo, tornando-se como um terceiro sistema de poder se associando nesta pauta com o estado e setores econômicos, desenhando uma nova configuração no processo de institucionalização da democracia de natureza participativa, na redistribuição do poder e na gestão das questões ambientais na busca de parcerias que priorize, desde o local ao global (SACHS, 1993).

Foi neste contexto, tanto no Brasil como em âmbito internacional, que se percebe a necessidade de promover ações e políticas em defesa do meio ambiente mais efetivas. Assim, as políticas públicas para o meio ambiente, que ao serem implementadas e gerenciadas trazem um paradoxo, pois ao mesmo tempo em que as demandas sociais surgem em decorrência da crise ambiental, exigindo do estado aparato políticoadministrativo, tornasse notória a perda de sua capacidade de determinar os rumos da dinâmica social e de proporcionar de forma eficiente as políticas que vão ao encontro dessas novas carências. Assim, procurando dar continuidade, e desdobramentos as decisões emanadas da Conferência do Rio de 92, a ONU realiza em Johannsburgo, África do Sul, em 2002, a Conferência Ambiental Rio +10 , especialmente no que diz respeito às questões socioambientais de combate à pobreza, a energias limpas e renováveis e as mudanças climáticas (conhecida como protocolo de Kyoto) (RISSATO et al., 2010; TAVOLARO, 1999).

\section{A construção das políticas ambientais no brasil}

Muito embora o Brasil chegue no século XX com algumas experiências significativas de proteção dos seus recursos naturais, e motivado pelo chamado 'progresso', industrialização, urbanização das cidades e expansão rumo à modernidade e inserção internacional, especialmente pelas pressões dos movimentos de proteção da natureza, ambiente favorável para organização da política ambiental brasileira e a normatização da exploração dos seus recursos naturais, tendo o Código Florestal como principal instrumento jurídico para a proteção dos ecossistemas florestais e diversos parques nacionais e estaduais, desvelando assim um contexto político e social favorável para o 'ambientalismo' brasileiro para a proteção da natureza (CÂMARA, 2013; MEDEIROS, 2006). 
Estes avanços e processos só foram também possíveis, graças ao protagonismo, pressão e articulação de diversos stakeholders, das agências multilaterais da ONU, dos poderes constituídos (executivo, legislativo e judiciário), da comunidade científica, de alguns setores do mercado, e de modo especial, da colaboração persistente e significativa de entidades e organizações ambientalistas e de movimentos sociais, nos âmbitos internacional, nacional, estadual e local.

Neste sentido, o processo de construção das políticas ambientais no Brasil, ocorreram por força das questões mais complexas sobre a pauta internacional do chamado DS. Vale ressaltar, que as temáticas ambientais não só se tornaram recorrentes, mas também estiveram presentes nas agendas dos governos e das políticas internacionais, e em especial nas principais agências do Sistema ONU (IPEA, 2011; JACOBI, 1999; RISSATO et al., 2010). Notadamente, por exemplo, o sistema GATT/OMC (Organização Mundial do Comércio) que tem como atribuições tratar das questões relacionadas ao comércio internacional, forçando a analisar e tratar sobre o impacto das questões ambientais no âmbito das negociações comerciais, o que influenciariam e influenciaram na formulação e regulamentação das políticas públicas econômicas, determinando novos padrões de produção e consumo nos países, pautado no conceito de DS, presente no acordo de Marraqueche (1994) (QUEIROZ, 2005).

Neste sentido, a implementação deste conceito de DS, não ocorrerá sem conflitos e sem decisório político, tanto no Brasil, quanto nos países. Nesta linha de pensamento, Nascimento (2012), ao conceituar as três dimensões do DS, chama à atenção para a necessidade de não perder de vista a dimensão política, sob pena da 'despolitização do DS', apontando para as estruturas e decisões políticas, fundamentais e necessárias no processo de mudanças frente aos conflitos de interesses na questão da sustentabilidade, e que "as mudanças passam necessariamente por instâncias econômicas e espaços políticos" (NASCIMENTO, 2012). Assim, as políticas públicas se constituem como importante instrumento da sociedade e de organização do estado, para atender aos cidadãos em suas necessidades básicas e de bem-estar, na garantia da oferta de serviços econômico, social, educacional, ambiental, dentre outros. Uma análise do processo de construção das políticas públicas deverá considerar o ambiente em que elas se desenvolvem, as pressões sociais, o conflito de interesses, a correlação de forças e poder, as decisões, dentre outros (SALHEB et al., 2009).

Conforme Peccatiello (2011), o termo 'políticas públicas' possui várias definições que privilegiam aspectos diversificados, como ações, processo decisório, atores políticos, planejamento, etc. Uma destas definições, o autor destaca o conceito de políticas públicas como ação de planejamento, e afirma que, as “Políticas públicas são mediações político-institucionais das inter-relações entre os diversos atores presentes no processo histórico-social em suas múltiplas dimensões (econômica, política, cultura, ambiental etc.) e são implementadas pelos atores políticos através de instituições públicas". A partir desta argumentação é plausível constatar a influência dos atores na execução das políticas públicas que direta ou indiretamente, interferem na formulação, na decisão e na fiscalização das políticas e estão relacionadas aos interesses de grupos hegemônicos da sociedade (PECCATIELLO, 2011).

Conceituando a política ambiental, Rissato et al. (2010) expressam que consiste em ações governamentais, que objetivam estabelecer instrumentos e normas para intervir nas atividades humanas, 
sociais e econômicas e minimizar os seus impactos no uso dos recursos naturais. Dessa forma, percebe-se que o meio ambiente ou mais especificamente, as problemáticas ambientais têm sido objeto da agenda pública no momento de formulação, implementação e gerenciamento de políticas públicas. O processo de formulação de políticas públicas ambientais se caracterizam pelo alto grau de complexidade, considerando a diversidade de atores envolvidos, e a eficiência de sua implementação, implica que quanto maior for o espaço na agenda governamental, maior será o incentivo político de competência institucional para atuar em sua gestão (RISSATO et al., 2010; RODRIGUES, 2011).

No Brasil, em resposta aos desafios de Estocolmo, 1972, e dos eventos subsequentes que apontamos anteriormente, a questão ambiental começou também a ser discutida, onde foram criados os primeiros instrumentos de gestão e estruturação da política ambiental, e a formulação de políticas ambientais com forte enfoque no 'comando' e 'controle', sendo essencialmente praticada pelo estado, a exemplo da criação em 1973 da Secretaria Especial de Meio Ambiente - SEMA. O modelo da política ambiental brasileira teve inicialmente como base o controle da poluição e a criação de unidades de conservação da natureza (CÂMARA, 2013; MAGRINI, 2001; PECCATIELLO, 2011).

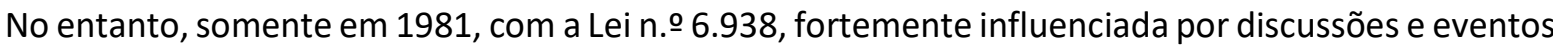
internacionais, houve a concretização de um sistema legal, onde se estabeleceu os objetivos, as ações e os instrumentos da Política Nacional de Meio Ambiente (PNMA). Criando os principais instrumentos de gestão da política ambiental, o CONAMA e SISNAMA, e o estabelecimento de padrões de qualidade ambiental, o zoneamento ambiental, a avaliação de impactos ambientais e o licenciamento e a revisão de atividades efetiva ou potencialmente poluidoras (art.9) (PECCATIELLO, 2011).

A que se ressaltar que as conquistas da PNMA, e a relevância das questões ambientais em nosso país, ganham força, a partir da década de 1980, com as pressões dos movimentos ambientalistas, e de organismos econômicos e internacional. Culminando com a promulgação da Constituição Federal de 1988, como um marco fundamental, quando estabeleceu que "todos tem direito ao meio ambiente ecologicamente equilibrado", o tornando assim, um direito fundamental das atuais e futuras gerações. Portanto, a Constituição impõe ao Governo essa obrigatória política pública (BRASIL, 1988).

\section{RESULTADOS E DISCUSSÃO}

\section{Etapas Histórico-Sociais Vinculadas Às Políticas Públicas No Brasil}

Sobre o processo histórico de periodização do desenvolvimento das políticas públicas ambientais no Brasil, Peccatielo (2011), expressa que de acordo com o Monosowski (1989), as políticas públicas ambientais do Brasil podem ser divididas em quatro abordagens estratégicas básicas, definindo estes momentos em função das características que cada uma mais expunha, observadas as suas principais legislações, refletindo o estado político e social a qual o país se encontrava. As etapas elencadas por Monosowski (1989) são: administração dos recursos naturais, o controle da poluição industrial, o planejamento territorial e a gestão integrada de recursos. Levando em consideração todos os fatores descritos, elaborou-se uma síntese 
contendo as cinco etapas de definição e os instrumentos de regulação das Políticas Públicas Ambientais, sistematizado a partir das propostas de Monosowski (1989) e Peccatiello (2011), que nos permitirá revelar os aspectos processuais que envolvem a formulação de políticas e o papel dos eventos internacionais.

\section{1ạ Etapa: Administração dos Recursos Naturais}

Este período que se inicia a partir da década de 1930, no auge da recessão econômica do século XX, até governos de ditadura militar no Brasil, é caracterizado pela regulação da apropriação de cada recurso natural em âmbito nacional, com foco nas necessidades das nascentes industrialização e urbanização. Importantes documentos e instrumentos de gestão foram criados, dando assim suporte à criação de áreas protegidas. Os principais instrumentos legais criados foram, o Código das Águas (1934), o Código de Mineração (1934), o Código Florestal (1934), o Código de Pesca (1938), o Estatuto da Terra (1964), Novo Código Florestal Brasileiro (1965).

\section{2a Etapa: O Controle da Poluição Industrial}

Esta segunda abordagem, ganha força a partir da década de 1970, influenciada pela Conferência da ONU de Estocolmo em 1972. Marcada por governos de ditaduras: a do governo Getúlio Vargas (1930-1945) e dos Militares (1964-1985). Como não podia deixar de ser, o aspecto autoritário e conservador da origem das políticas públicas brasileiras também veio a refletir na política ambiental. Até metade dos anos 1980, houveram sucessivas etapas da política ambiental caracterizadas pela contradição e pela descontinuidade de algumas 'conquistas' na área ambiental. O enfoque e uma das características essenciais do Estado brasileiro, neste período, eram traduzidos no seu "caráter desenvolvimentista e conservador", ou seja, não se tratava de um Estado do bem-estar social, mas, sim, promotor do "progresso" (PECCATIELLO, 2011).

Marcado pela pouca disposição de imposição de padrões de emissão ao agente poluidor, por gerar conflito com os objetivos centrais do governo brasileiro de crescimento econômico, Poluição = Progresso. Focados apenas na agenda de comando e controle, e em resposta a denúncias de poluição industrial e rural. São os principais instrumentos do período, I Plano Nacional de Desenvolvimento (1972-1974); II Plano Nacional de Desenvolvimento (1975-1979), tinham como objetivos colocar o Brasil entre as 10 (dez) nações mais desenvolvidas; Criação da Secretaria Especial do Meio Ambiente (SEMA), em 1973, vinculada ao Ministério do Interior; Criação do Comitê Especial de Estudos Integrados de Bacias Hidrográficas (CEEIBH) 1978; e a criação de Comitês Executivos em diversas Bacias Hidrográficas: no Paraíba do Sul, no São Francisco e no Ribeira de Iguape.

\section{3a Etapa: O Planejamento Territorial}

Se caracteriza pela tentativa de solucionar os problemas ocorridos na fase anterior. A ênfase é dada pela abordagem estratégica de planejamento territorial, devido à intensa urbanização e acentuado crescimento da população nas regiões metropolitanas, motivadas especialmente pelos Planos Desenvolvimentistas ocorridos entre os anos 1972-1974 (Plano I) e 1975-1979 (Plano II) de crescimento da 
economia. $\mathrm{O}$ que vão trazer também impactos sobre o meio ambiente, mesmo diante do denuncismo e pressão internacional sobre a escassez dos recursos naturais e a necessidade de preservá-los.

O Estado do século XXI continua exercendo o papel de regulador na ordem política, social e territorial, com o seu poder de decisão adota determinadas medidas que fomenta a degradação ambiental Temos como principais instrumentos, A institucionalização da Avaliação dos Impactos Ambientais (AIA), nos projetos de desenvolvimento, exigências do BIRD e BID; Lei Federal no 6.766/1979 - Parcelamento do Solo Urbano, estabelece regras para loteamentos urbanos, proibidos em áreas de preservação ecológicas, naquelas onde a poluição representa perigo à saúde e em terrenos alagadiços; Lei no 6.803/1980 - Lei do Zoneamento Industrial na Áreas Críticas de Poluição; Lei no 7.347/1985 da Ação Civil Pública. Trata da ação civil pública de responsabilidades por danos causados ao meio ambiente. Criação do órgão regulador (Serviço Florestal Brasileiro) e do Fundo de Desenvolvimento Florestal. Decreto no 91.145/1985. Foi criado o Ministério do Desenvolvimento Urbano e do Meio Ambiente (MELLO-THÉRY, 2011).

\section{4a Etapa: A Gestão Integrada de Recursos}

Esta fase, tem início na década de 1980 até os anos 2000. Marcados inicialmente pela criação da Política Nacional de Meio Ambiente (Lei no 6.938 de 1981) e dos principais Instrumentos de Gestão. Ressaltase que os conceitos destes documentos são incorporados na integra na Constituição de 1988, em seu Capítulo VI-Do Meio Ambiente.

Assim, é mantido o caráter conservacionista da política ambiental, a restrição ao uso dos recursos naturais, a integração dos três níveis de governo e a responsabilização do Estado por suas ações ao meio ambiente. Diante de uma situação urbano-ambiental alarmante, com desigualdade de renda, e concentração urbana nas cidades. No bojo das conquistas socioambientais consagradas na Constituição de 1988, assegurando um caráter participativo e descentralizado no processo decisório, Peccatiello (2011), citando (VIEIRA et al., 1989), afirmam: “Acirra-se a contradição entre uma economia predadora e poderosas pressões de movimentos e interesses nacionais e internacionais. Assim como a economia, o meio ambiente também se globaliza. Redefinem-se os temas da política ambiental. Evidencia-se a necessidade de um novo pacto entre as nações". São os principais instrumentos, Lei Federal no 6.938/1981 - Institui a PNMA, Cria o SISNAMA, e o CONAMA; Promulgação da Constituição Federal de 1988, responsabilidades compartilhadas entre os três entes federativos (Capítulo II, art. 23); da Ordem Econômica e Financeira (Título VII, art. 170); Política Urbana (Capítulo II, art. 182); Meio Ambiente (Capítulo VI, art. 225); Lei no 7.735/1989 - Cria o IBAMA e reestrutura os órgãos públicos sobre a questão ambiental; Lei 8.490/1992 - A criação do Ministério do Meio Ambiente-MMA, a Lei 9.605/98 - Lei de Crimes Ambientais, instrumentos de direito ambiental.

\section{5a Etapa: O Futuro do Planeta - Agenda Global para o Século 21}

Este período se caracterizou principalmente pela forte influência da Conferência das Nações Unidas sobre o Meio Ambiente e Desenvolvimento - CNUMAD, também conhecida como ECO 92, e a RIO +20 até os dias atuais. Os importantes e significativos documentos e oficiais globais: a Carta da Terra, as Convenções 
sobre Biodiversidade, Desertificação e Mudanças Climáticas, a Declaração de princípios sobre Florestas, a Declaração do Rio sobre Ambiente e Desenvolvimento e a Agenda 21, esta última, base para que cada país elabore o seu plano de preservação do meio ambiente, dentre outros documentos.

Será observado no período, a consolidação do processo de construção da concepção e conceito básico de desenvolvimento sustentável, conciliando o ambiental, social e econômico, (Triple Bottom Line). Instrumentos a partir dos anos 2.000, Lei Federal 9.985/2000 - Instituí o Sistema Nacional de Unidades de Conservação (SNUC) - Conservação dos recursos naturais e criação de áreas protegidas; Lei 10.257/2001 Estatuto da Cidade, Planejamento e Desenvolvimento urbano com respeito ao Meio Ambiente; Lei no 11.105/2005 de Biossegurança estabeleceu sistemas de fiscalização sobre as diversas atividades que envolvem organismos modificados geneticamente; Lei no 11.284/2006 de Gestão de Florestas Públicas normatizou o sistema de gestão florestal em áreas públicas e criou um órgão regulador (Serviço Florestal Brasileiro). Esta lei criou também o Fundo de Desenvolvimento Florestal; Lei 11.445/2007 Estabeleceu a Política Nacional de Saneamento Básico (drenagem urbana, abastecimento de água, esgotamento sanitário e resíduos sólidos); Lei 12.305/2010 - Institui a Política Nacional de Resíduos Sólidos (PNRS). Lei 12.651/2012 Novo Código Florestal Brasileiro - Define a proteção do meio ambiente natural é obrigação do proprietário, manter espaços protegidos, Áreas de Proteção Permanentes (APPs) e Reserva Legal (RL).

O início das ações governamentais no campo das políticas de meio ambiente foi marcado por duas preocupações básicas: a racionalização do uso e exploração dos recursos naturais e a definição de áreas de preservação permanente, estabelecendo assim, alguns limites à propriedade privada.

\section{CONCLUSÕES}

A recuperação de eventos internacionais, acontecimentos climáticos e suas ligações e influências mostra-se fundamental, pois nos permite compreender a conexão entre o micro e o macro. Além disso, é possível cercar elementos que emergem internacionalmente e impactam na realidade de um país, como discutido na presente pesquisa, o caso do Brasil. Identificando lampejos de protagonismo e influências múltiplas que culminaram nas nossas atuais políticas ambientais.

Como também já destacado neste estudo, os diversos acontecimentos históricos e os eventos e mobilizações internacionais, foram fundamentais para a estruturação de uma governança ambiental global, tornando a temática do meio ambiente, a segunda maior área em termos de documentos oficiais internacionais, perdendo apenas para o comércio internacional. Tais como, a Convenção-Quadro das Nações Unidas sobre Mudança do Clima, a Convenção sobre Diversidade Biológica e a Convenção das Nações Unidas de Combate à Desertificação, dentre outras, o que também resultaram em impactos em termos de normatizações no âmbito da OMC.

Longe de afirmar que estes acordos e pactos assumidos (com algumas limitações e desacordos em sua propositura), foram implementados e estão sendo cumpridos integralmente, considerando a sua complexidade e desafios de ruptura de paradigmas dos atuais modus operandi do modelo de desenvolvimento ocorrendo há mais de um século, mas que se tornou a bússola possível e necessária, de 
caráter planetário, que veio a influenciar as nações, em especial os países-membros da ONU (uns mais outros menos, considerando o seu contexto socio-político-econômico) para um esforço e a adoção de um novo padrão de desenvolvimento capaz de conciliar desenvolvimento econômico, social e ambiental, para atender as necessidades básicas e fundamentais das atuais e futuras gerações, rumo a preservação do planeta.

Muito embora, temos assistido, especialmente em nosso país, ameaças e descumprimento às metas propostas, em termos de preservação e proteção dos nossos recursos naturais, e de mudanças lentas nas emissões de gases de efeito estufa, de alterações e precarização dos marcos regulatórios ambiental, e de índice ainda alto de pobreza, decorrentes de uma economia de produção e consumo não sustentável e concentradora de renda e de riqueza. Ainda assim, entendemos que houveram avanços significativos e relativos cumprimentos nas metas e acordos assumidos pelo Brasil. Assim, a partir da década de 90, o país assumiu novas feições política, econômica, tecnológica, em termos institucionais e na gestão pública, assegurando a sua inserção neste novo padrão globalizado de governança ambiental (CÂMARA, 2013).

Como demonstrado ao longo desta pesquisa, o Brasil recebeu grande influência destes eventos e do conceito DS, mas não só foi influenciado, mas também tem assumido e tem exercido protagonismo nas diversas agendas globais das políticas ambientais, podendo ser destacadas, as relevantes contribuições do país, no alcance dos objetivos da CDB, a exemplo da implementação da lei do SNUC, resultando na conservação e proteção de $74 \%$ de suas florestas, em relação às áreas protegidas do mundo, entre os anos 2003 e 2008, por exemplo, e na criação dos instrumentos de proteção de sua biodiversidade (IPEA, 2016).

No entanto, os desafios permanecem, existe ainda um longo caminho a ser percorrido em termos de governança ambiental para o alcance do desenvolvimento sustentável. As dificuldades para a implementação das políticas ambientais brasileiras podem ser encontradas na complexidade do ambiente jurídico e de sua interface com as demais políticas públicas, com a prevalência da política econômica e a falta de diálogo com as demais políticas, sociais e ambientais; nas fragilidades na estrutura administrativa; nas sobreposições de competências e ações; na insuficiência dos recursos de financiamento das políticas ambientais; nas fragilidades no processo de descentralização, de gestão democrática e controle social; e no processo decisório sobre essas políticas, contexto ao qual ainda se soma a alta degradação ambiental.

Para enfrentar tais problemáticas, no âmbito internacional, os acordos e pactos continuam em processos de aperfeiçoamento e adequações diante dos desafios e das realidades vigentes, assim como o estabelecimento e a adoção de novas metas para o desenvolvimento sustentável. Um exemplo é a recente aprovação pela Assembleia das Nações Unidades, realizada em Nova lorque, em dezembro de 2016, de uma agenda global, com os Objetivos do Desenvolvimento Sustentável (ODS), conhecida como Agenda 2030, em continuidade e com ampliação de novas metas dos ODMs, de 2000. Foi estabelecida, também, anualmente, a realização do SDG Business Fórum (Fórum Político de Alto Nível das Nações Unidas), evento que tem como objetivos revisar o progresso e orientar os esforços globais para o cumprimento da Agenda 2030, reunindo líderes mundiais da ONU, dos governos, dos empresários e da sociedade civil, sob a coordenação da Câmara de Comércio Internacional (International Chamber of Commerce - ICC), pelo Departamento de Assuntos 
Econômicos e Sociais das Nações Unidas (UN DESA) e pelo Pacto Global da ONU, constituindo-se em importante ferramenta e instrumento de monitoramento dos ODS.

Por um lado, pudemos vislumbrar os grandes avanços ocorridos no marco jurídico ambiental brasileiro, em sua gestão e governança ambiental, com limites e retrocessos ao longo de quase cinco décadas e vários governos; por outro, assistimos a um futuro ainda incerto, com o novo governo eleito, que ainda não tomou posse na Presidência da República, até a defesa desta dissertação. Contudo, segundo especialistas, há em boa parte da comunidade científica e da comunidade internacional, preocupação com as possíveis desregulações, flexibilizações e retrocessos em nossa legislação e governança ambiental, tendo como exemplos a possível indicação de fusão dos ministérios da agricultura e do meio ambiente, o possível não cumprimento das metas assumidas de redução do desmatamento das nossas florestas e das metas do acordo do clima, dentre outras. Isso seria um grande e grave retrocesso para o futuro do Brasil, de consequências incalculáveis, considerando o seu patrimônio em termos de recursos naturais vitais para a sobrevivência do planeta.

\section{REFERÊNCIAS}

ALONSO, A.; VALERIANO, C.. Ciências Sociais e Meio Ambiente no Brasil: um balanço bibliográfico. BIB - Revista Brasileira de Informações Bibliográficas em Ciências Sociais, ANPOCS, n.53, p.35-78, 2002.

ARENDT, H.. A Condição Humana. The Human Condition. 10 ed. Rio de Janeiro: Forense Universitária, 2007.

BRASIL. Constituição da República Federativa do Brasil. 1988.

BRUNDTLAND. Our common future: from one Earth to one World: the World Commission on Environment and Development. Oxford: Oxford University Press, 1987.

CÂMARA, J. B. D.. Governança ambiental no Brasil: ecos do passado. Revista de Sociologia e Política, v.21, n.46, p.125146, 2013.

CARSON, R.. Primavera Silenciosa. 2 ed. São Paulo: Melhoramentos, 1969.

GANEM, R. S.. Conservação da Biodiversidade: Legislação e Políticas Públicas. Brasília: Câmara dos Deputados, 2011.

IPEA. Instituto de Pesquisa Econômica Aplicada. O Brasil na Governança das Grandes Questões Ambientais Contemporâneas. Brasília: IPEA, 2011.

IPEA. Instituto de Pesquisa Econômica Aplicada. Meio Ambiente na Agenda Internacional: Implementação no Brasil das Convenções do Rio Sobre Biodiversidade, Clima e Desertificação. Brasília: IPEA, 2016.

JACOBI, P. R.. Meio Ambiente e Sustentabilidade. In: O município no século XXI: cenários e perspectivas. São Paulo: Fundação Prefeito Faria Lima, 1999.
HARARI, Y. N.. Sapiens: Uma breve história da humanidade. Tradução Janaína Marcoantonio. 32 ed. Porto alegre: L\&PM, 2018.

LEFF, E.. Racionalidade ambiental: a reapropriação social da Natureza. Rio de Janeiro: Civilização Brasileira, 2006.

MARCO, C. M.; MEZZAROBA, O.. O Direito Humano ao Desenvolvimento Sustentável: Contorno históricos e Conceituais. Veredas do Direito, v.14, n.29, p.323-349, 2017. DOI: $\underline{\text { http://dx.doi.org/10.18623/rvd.v14i29.1066 }}$

MARCONATTO, D. A. B.; TREVISAN, M.; PEDROZO, E. A.; SAGGIN, K. D.; ZONIN, V. J.. Saindo da Trincheira do Desenvolvimento Sustentável- uma Nova Perspectiva para a Análise e a Decisão em Sustentabilidade. Revista de Administração Mackenzie, v.14, p.15-43, 2013.

MAGRINI, A.. Política e Gestão Ambiental: conceitos e instrumentos. Revista Brasileira de Energia, v.8, n.2, p.1-8, 2001.

MEADOWS, D. H.; MEADOWS, D. L.; RANDERS, J.; BEHRENS III, W. W.. The Limits to Growth: A Report for The Club of Rome's Project on the Predicament of Mankind. New York: Universe Books, 1972.

MEDEIROS, R.. Evolução das tipologias e categorias de áreas protegidas do Brasil. Ambiente \& Sociedade, v.9, n.1, p.1$25,2006$.

MELLO-THÉRY, N. A.. Meio ambiente, globalização e políticas públicas. Revista Gestão \& Políticas Públicas, v.1, n.1, p.133161, 2011.

NASCIMENTO, E. P.. Trajetória da sustentabilidade: do ambiental ao social, do social ao econômico. Estudos Avançados, v.26, n.74, p.51-64, 2012. 
ONU. Organização das Nações Unidas. Report of the United Nations Conference on the Human Environment. Stockholm: ONU, 1972.

PECCATIELlO, A. F. O.. Políticas Públicas Ambientais no Brasil: da administração dos recursos naturais (1930) à criação do Sistema Nacional de Unidades de Conservação (2000). Desenvolvimento e Meio Ambiente, n.24, p.71-82, 2011.

PIOVESAN, A.; TEMPORINI, E R.. Pesquisa exploratória: procedimento metodológico para o estudo de fatores humanos no campo da saúde pública. Revista Saúde Pública, n.29, p.318-325, 1995.

PHILIPPI, A. J.; SOBRAL, M. C.; FERNANDES, V.; SAMPAIO, C. A. C.. Desenvolvimento sustentável, interdisciplinaridade e ciências ambientais. Revista Brasileira de Pós-Graduação, v.10, n.21, p.509-533, 2013.

POTT, C. M.; ESTRELA, C. C.. Histórico ambiental: desastres ambientais e o despertar de um novo pensamento. Estudos Avançados, n.31, p.271-283, 2017. DOI: http://dx.doi.org/10.1590/s0103-40142017.31890021

QUEIROZ, F. A.. Meio ambiente e comércio na agenda internacional: A questão ambiental nas negociações da OMC e dos blocos econômicos regionais. Ambiente \& Sociedade, v.8, n.2, p.1-13, 2005.

RIBEIRO, W. C.. Desenvolvimento Sustentável e Segurança Ambiental Global. Revista Bibliográfica de Geografía y Ciencias Sociales, v.21, n.312, p.742-798, 2001.

RISSATO, D.; SPRICIGO, B.. A política ambiental no brasil no período de 1970-1999. Revista Ciências Sociais em Perspectiva, v.9, n.16, p.1-17, 2010.

RODRIGUES, D. F.. Dinâmica institucional, políticas públicas e o desenvolvimento político ambiental brasileiro.

Sustentabilidade em Debate, v.2, n.2, p.149-164, 2011.

ROMEIRO, A. R.. Desenvolvimento sustentável: uma perspectiva econômico-ecológica. Estudos Avançados, v.26, n.74, p.65-92, 2012. DOI: http://dx.doi.org/10.1590/S0103$\underline{40142012000100006}$
SACHS, I.. Estratégias de transição para o século XXI. In: BURSZTYN, M; MENDES, A.; SACHS, I.; BUARQUE, C.; DOWBOR, L.; AGUIAR, R. C.; BECKER, B.; LEITÃO, P.. Para Pensar o Desenvolvimento Sustentável. São Paulo: Brasiliense, 1993, p.29-56

SALHEB, G. J. M.; NETO, H. A. P. P.; OLIVEIRA, I. M.; JUNIOR, M. F. A.; BOETTGER, R. J. C. S.; MONTEIRO, V. C. S.. Políticas Públicas e Meio Ambiente: reflexões preliminares. Revista Internacional de Direito Ambiental e Política, n.1, p.1- 26, 2009.

SANTOS, B. S.. Para além do Pensamento Abissal: Das linhas globais a uma ecologia de saberes. Revista de Ciências Sociais, n.78, p.3-46, 2007.

SCHNEIDER, O.. Cooperativismo e desenvolvimento sustentável Cooperativismo e desenvolvimento sustentável. Otra Economía, v.9, n.16, p.94-104, 2015.

TAVOLARO, S. B. F.. A Questão Ambiental: sustentabilidade e políticas públicas no Brasil. Ambiente $\&$ Sociedade, v.2, n.5, 1999.

THEIS, I. M.. Considerações sobre os limites energéticos do crescimento econômico. Revista de Ciências Humanas, v.14, n.19, p.117-148, 1996

UNESCO. Organização Das Nações Unidas Para A Educação. A Ciência e a Cultura. 2018.

VIEIRA, A. S.. Meio ambiente e desenvolvimento sustentável: fontes para compreensão do discurso político-ambiental do governo brasileiro. Revista IBICT, v.21, n.1, p.7-13, 1992.

VOSGERAU, D. S. A. R.; ROMANOWSKI, J. P.. Estudos de revisão: implicações conceituais e metodológicas. Revista Diálogo Educacional, v.14, n.41, p.165-189, 2014. DOI: http://dx.doi.org/10.7213/dialogo.educ.14.041.DS08

WOLKMER, M. F. S.; PAULITSCH, N. S.. ÉTICA AMBIENTAL E CRISE ECOLÓGICA: reflexões necessárias em busca da sustentabilidade. Veredas do Direito, v.8, n.16, p.211-233, 2011.

A CBPC - Companhia Brasileira de Produção Científica (CNPJ: 11.221.422/0001-03) detém os direitos materiais desta publicação. Os direitos referem-se à publicação do trabalho em qualquer parte do mundo, incluindo os direitos às renovações, expansões e disseminações da contribuicão, bem como outros direitos subsidiários. Todos os trabalhos publicados eletronicamente poderão posteriormente ser publicados em coletâneas impressas sob coordenação da Sustenere Publishing, da Companhia Brasileira de Produção Científica e seus parceiros autorizados. Os (as) autores (as) preservam os direitos autorais, mas não têm permissão para a publicação da contribuição em outro meio, impresso ou digital, em português ou em tradução. 